\title{
Reexamination of Yeast Strains Classified as Torulaspora delbrueckii (Lindner)
}

\author{
YUJI ODA, ${ }^{1 *}$ MIHE YABUKI, ${ }^{2}$ KENZO TONOMURA,${ }^{1}$ AND MASAHITO FUKUNAGA ${ }^{2}$ \\ Department of Food Science and Technology ${ }^{1}$ and Faculty of Pharmacy and Pharmaceutical Sciences, ${ }^{2}$ \\ Fukuyama University, Fukuyama, Hiroshima 729-02, Japan
}

\begin{abstract}
Twenty-eight yeast strains presumed to represent Torulaspora delbrueckii were analyzed by randomly amplified polymorphic DNA-PCR analysis. Four strains (HUT 7161, IFO 1138, IFO 1145, and IFO 1956) that were considerably different from the type strain were further investigated. Morphological and physiological characteristics revealed that strains HUT 7161 and IFO 1145 belong to the genus Debaryomyces rather than the genus Torulaspora, and the former strain may represent Debaryomyces hansenii. Strains IFO 1138 and IFO 1956 were classified as either Saccharomyces castellii or Saccharomyces dairensis by identification keys involving physiological tests. On the basis of analysis of the sequences of two rRNA internal spacer regions, strains IFO 1138 and IFO 1956 were closely related to $S$. castellii and strains HUT 7161 and IFO 1145 were outside members of the genera Torulaspora, Zygosaccharomyces, and Saccharomyces.
\end{abstract}

Torulaspora species include some interesting strains that are applied to the industrial production of bread (17) and wine (4). The genus Torulaspora was defined in 1895 by Lindner (12) soon after Hansen began his studies on yeast taxonomy in the late 19th century (8). This genus was incorporated into the genus Saccharomyces, together with the genus Zygosaccharomyces in 1952 by Lodder and Kreger-van Rij (13), and was subsequently redefined in 1975 by van der Walt and Johannsen (22). The history of Torulaspora reflects its close relationship with Saccharomyces and Zygosaccharomyces $(2,24)$. Recently, James et al. (10) proposed that the genus Torulaspora may encompass two species of Zygosaccharomyces, Z. mrakii and Z. microellipsoides, based on the sequence analysis of the internal transcribed spacer (ITS) region between $18 \mathrm{~S}$ and $28 \mathrm{~S}$ rRNA genes.

We have investigated electrophoretic karyotypes of Torulaspora delbrueckii, Torulaspora globosa, and Torulaspora pretoriensis and found that several strains of $T$. delbrueckii differed from the type strain (16). These results led us to reexamine the strains classified as $T$. delbrueckii. In the present experiments, 28 strains of $T$. delbrueckii were surveyed by randomly amplified polymorphic DNA (RAPD)-PCR analysis. The strains showing a pattern different from that of the type strain were further characterized by conventional identification tests and comparison with ITS sequences.

\section{MATERIALS AND METHODS}

Organisms and culture. Twenty-eight strains of the yeast $T$. delbrueckii (Table 1) were grown on a medium containing $1 \%$ yeast extract, $2 \%$ peptone, $2 \%$ glucose, and $2 \%$ agar at $30^{\circ} \mathrm{C}$ for 2 days.

RAPD-PCR and data analysis. Each $25 \mu \mathrm{l}$ of reaction mixture contained 11.3 $\mu \mathrm{l}$ of sterilized distilled water, $2.5 \mu \mathrm{l}$ of $10 \times$ amplification buffer, $2.0 \mu \mathrm{l}$ of $25 \mathrm{mM}$ $\mathrm{MgCl}_{2}, 2.0 \mu \mathrm{l}$ of a $10 \mathrm{mM}$ deoxynucleoside triphosphate mixture, $0.2 \mu \mathrm{l}$ of Taq DNA polymerase ( $5 \mathrm{U} / \mu \mathrm{l}$; Greiner Japan, Tokyo, Japan), $5.0 \mu \mathrm{l}$ of $10 \mu \mathrm{M}$ primer (Table 2), and $2.0 \mu$ lof genomic DNA prepared by the method of Valente et al (20). The reaction mixture was overlaid with mineral oil and placed in a thermal cycler programmed for $2 \mathrm{~min}$ at $98^{\circ} \mathrm{C}$, followed by 37 cycles of $15 \mathrm{~s}$ at $98^{\circ} \mathrm{C}, 90 \mathrm{~s}$ at $32^{\circ} \mathrm{C}$, and $100 \mathrm{~s}$ at $72^{\circ} \mathrm{C}$ for both decamers. Different cycling conditions were used for amplification using the M13 primer $\left(2 \mathrm{~min}\right.$ at $98^{\circ} \mathrm{C}$, followed by 42 cycles of $15 \mathrm{~s}$ at $98^{\circ} \mathrm{C}, 90 \mathrm{~s}$ at $50^{\circ} \mathrm{C}$, and $100 \mathrm{~s}$ at $72^{\circ} \mathrm{C}$ ). The PCR products were resolved by electrophoresis in $1.4 \%$ agarose gels in $0.5 \times$ TBE buffer $(45 \mathrm{mM}$ Tris-borate,

\footnotetext{
* Corresponding author. Mailing address: Department of Food Science and Technology, Fukuyama University, Fukuyama, Hiroshima 729-02, Japan. Fax: 81-849-36-2023. E-mail: oda@fubac.fukuyama-u .ac.jp.
}

$\mathrm{pH} 7.5,1 \mathrm{mM}$ EDTA) with $0.5 \mu \mathrm{g}$ of ethidium bromide per ml. Lambda DNA digested with EcoT14I was used as a length standard.

Genetic distance was calculated manually as the number of different bands between two patterns divided by the sum of all bands in the same patterns. A value of 0 indicates that the two strains had identical patterns, and a value of 1 indicates that the two strains had completely different patterns. The dice matrix obtained from these data was used to construct an unrooted dendrogram using the NEIGHBOR program in the PHYLIP package, version $3.5 \mathrm{c}(6)$.

Morphological and physiological examinations. Conventional taxonomic tests were carried out by the standard methods (3). The physiological examinations include fermentation of sugars; assimilation of carbon and nitrogen compounds; growth temperature; growth in the presence of cycloheximide, acetic acid, and large amounts of glucose; and vitamin requirements.

Amplification of ITS regions and sequence analysis. The region spanning ITS1, ITS2, and the intervening 5.8S rRNA gene was amplified by PCR using the primer set pITS1 and pITS4 (Table 2) under modified conditions $\left(2 \mathrm{~min}\right.$ at $95^{\circ} \mathrm{C}$, followed by 33 cycles of $45 \mathrm{~s}$ at $95^{\circ} \mathrm{C}, 45 \mathrm{~s}$ at $55^{\circ} \mathrm{C}$, and $45 \mathrm{~s}$ at $72^{\circ} \mathrm{C}$, and $10 \mathrm{~min}$ at $72^{\circ} \mathrm{C}$ for a final extension). The DNA fragments were purified and sequenced as previously described (7). The nucleotide sequence was analyzed by the dideoxy chain termination method with the custom-synthesized primers YT8FF, YT8F1, YT6R1, and YT58R (Table 2). Both strands of each PCR-amplified fragment were sequenced. Sequence alignment, a similarity matrix, and a neighbor-joining phylogenetic tree were created on a Macintosh personal computer with the DNASTAR program (DNASTAR Inc., Madison, Wis.) and the CLUSTAL V software package $(9,19)$.

Nucleotide sequence accession numbers. The DNA sequences, including partial $18 \mathrm{~S}$ and $28 \mathrm{~S}$ rRNA genes and the entire ITS regions of the eight $T$. delbrueckii strains (Table 1), have been assigned DDBJ, EMBL, and GenBank accession numbers D89598 to D89605. In addition, retrieved sequences of the species of Torulaspora (10), Zygosaccharomyces (10), and Saccharomyces (D89886 to D89898) were used in this study.

\section{RESULTS}

RAPD-PCR analysis. RAPD-PCR patterns of the 28 strains of $T$. delbrueckii using decamer 2 are shown in Fig. 1. Each strain gave a total of 3 to 11 distinct bands ranging from 0.2 to $3.5 \mathrm{~kb}$. Most strains contained some conserved bands that appeared in the type strain. However, six strains-HUT 7161 (lane 5), IFO 0381 (lane 7), IFO 1138 (lane 11), IFO 1145 (lane 12), IFO 1956 (lane 20), and IFO 1959 (lane 21)-were discriminated from the type strain, SANK $50188^{\mathrm{T}}$ (lane 1). The patterns of the six strains were different from each other except for strains IFO 1138 and IFO 1956, which shared most bands. Similar patterns were observed among the 28 strains with the use of two other primers, M13 and decamer 1 (data not shown). Because the whole pattern was not always the same in independent experiments, only the reproducible bands were scored. The data for 90 distinct bands obtained with all three primers were combined to construct a dendrogram by the 
TABLE 1. List of Torulaspora delbrueckii strains used

\begin{tabular}{|c|c|c|c|c|}
\hline Strain no. & Strain designation ${ }^{a}$ & Other name(s) ${ }^{a}$ & Original denomination & ITS sequence accession number \\
\hline 1 & SANK $50188^{\mathrm{T}}$ & IFO 0955, CBS $1146^{T}$ & S. delbrueckii & D89598 \\
\hline 2 & SANK 50268 & & S. rosei & \\
\hline 3 & SANK 50371 & IFO 0428, CBS 1148 & T. rosei & \\
\hline 4 & HUT 7160 & & S. rosei & \\
\hline 5 & HUT 7161 & & S. rosei & D89599 \\
\hline 6 & HUT 7183 & & S. delbrueckii & \\
\hline 7 & IFO 0381 & & Tonula colliculosa & D89600 \\
\hline 8 & IFO 0421 & CBS 8247 & & D89601 \\
\hline 9 & IFO 0704 & CBS 158 & Torulopsis stellata var. cambresieri & \\
\hline 10 & IFO 0876 & & Torulopsis dattila var. tokyoensis & \\
\hline 11 & IFO 1138 & NRRL Y-2296 & S. delbrueckii & D89602 \\
\hline 12 & IFO 1145 & NRRL Y-1689 & S. rosei & D89603 \\
\hline 13 & IFO 1172 & CBS 404 & S. torulosus & \\
\hline 14 & IFO 1176 & CBS 3018 & & \\
\hline 15 & IFO 1179 & CBS 1150 & T. rosei & \\
\hline 16 & IFO 1180 & CBS 1151 & T. rosei & \\
\hline 17 & IFO 1255 & & Debaryomyces nilssonii & \\
\hline 18 & IFO 1621 & CBS $3003^{\mathrm{T}}$ & $S$. inconspicuus & \\
\hline 19 & IFO 1626 & CBS $2733^{\mathrm{T}}$ & S. vafer & \\
\hline 20 & IFO 1956 & NCYC 147 & Torula alactosa & D89604 \\
\hline 21 & IFO 1959 & NCYC 696 & S. fermentati & D89605 \\
\hline 22 & IFO 10245 & ATCC 42213 & Torulopsis taboadae & \\
\hline 23 & NRIC 1393 & IFO 0424 & & \\
\hline 24 & NRIC 1395 & IFO 0469, CBS 705 & Z. mongolicus & \\
\hline 25 & NRIC 1398 & IFO 0422, CBS $818^{T}$ & T. fermentati & \\
\hline 26 & IFO 0431 & & T. rosei & \\
\hline 27 & IFO 1083 & ATCC 2507 & Torulopsis colliculosa & \\
\hline 28 & IFO 1129 & CBS 817 & S. rosei & \\
\hline
\end{tabular}

${ }^{a}$ ATCC. American Type Culture Collection; CBS, Centraalbureau voor Schimmelcultures; HUT, Faculty of Technology, Hiroshima University; IFO, Institute for Fermentation, Osaka; NCYC, National Collection of Yeast Cultures; NRRL, Northern Regional Research Center; NRIC, Tokyo University of Agriculture; SANK, Sankyo Co.

UPGMA (unweighted pair group method with averages) method (Fig. 2). According to Messner et al. (14), similarity values within the range of 30 to $50 \%$ in RAPD-PCR analysis are considered to be characteristic for closely related species. As described below, we then compared the four strains showing less than $50 \%$ similarity to the type strain with the four representative strains showing 50 to $100 \%$ similarity. The strain number and percent similarity are as follows: HUT 7161, 25; IFO 1138, 30; IFO 1956, 30; IFO 1145, 40; IFO 0381, 51; IFO 1959, 57; IFO 0421, 84; and SANK 50188 ${ }^{\mathrm{T}}, 100$.

Morphological and physiological characteristics. The vegetative cells of eight strains were globose to ellipsoidal, single or in pairs. HUT 7161 cells $(0.8$ to $2.0 \mu \mathrm{m}$ by 2.0 to $3.8 \mu \mathrm{m})$ were smaller than those of the other seven strains $(2.0$ to $4.0 \mu \mathrm{m}$ by 3.0 to $7.5 \mu \mathrm{m}$ ).

Vegetative cells of strain IFO 1956 were directly transformed into asci containing one to three globose ascospores on McClary's acetate agar, although the sporulation rate was quite low. No ascospores were observed in the other seven strains when they were incubated on McClary's acetate agar, dilute V8 agar, Gorodkowa agar, corn meal agar, and YM agar. However, the five strains SANK 50188 ${ }^{\mathrm{T}}$, HUT 7161, IFO 0381, IFO 1145, and IFO 1959 formed a protuberance, the conjugation between a cell and its bud, and occasionally an ascus with spherical spores in a liquid medium containing $0.67 \%$ yeast nitrogen base without amino acids (Difco) and $0.5 \%$ glucose. The manner in which asci arose was characteristic of the genera Torulaspora and Debaryomyces (3).

When the physiological patterns were compared, the profiles of four strains, SANK $50188^{\mathrm{T}}$, IFO 0381, IFO 0421, and IFO 1959, almost fitted the description of $T$. delbrueckii (3). Strain HUT 7161 resembled Debaryomyces hansenii because only this strain lacked fermentation ability but assimilated D-xylose, Larabinose, cellobiose, arbutin, melibiose, melezitose, erythritol, D-glucuronate, succinate, and citrate as carbon sources and ethylamine as the nitrogen source (3). Strains HUT 7161 and

TABLE 2. DNA primers used for PCR amplification and ITS sequencing

\begin{tabular}{llll}
\hline \multicolumn{1}{c}{ Primer } & \multicolumn{1}{c}{ Sequence $\left(5^{\prime}-3^{\prime}\right)$} & \multicolumn{1}{c}{ Application } \\
\hline Decamer 1 & ACGGTCTTGG & RAPD-PCR \\
Decamer 2 & TGCCGAGCTG & RAPD-PCR \\
M13 & GAGGGTGGCGGTTCT & RAPD-PCR & 18S rRNA \\
PITS1 & TCCGTAGGTGAACCTGCGG & Forward primer (ITS amplification) \\
pITS4 & TCCTCCGCTTATTGATATG & Reverse primer (ITS amplification) \\
YT8FF & CGTAGGTGAACCTGCGGAAGGATC & ITS1 sequencing & 28S rRNA \\
YT8F1 & GCATCGATGAAGAACGCAG & ITS1 sequencing & 18S rRNA \\
YT6R1 & CGCTTATTGATATGCTTAAGTTCAGC & ITS2 sequencing & 5.8S rRNA \\
YT58R & ATGACGCTCAAACAGGCAT & ITS2 sequencing & 28S rRNA \\
\hline
\end{tabular}




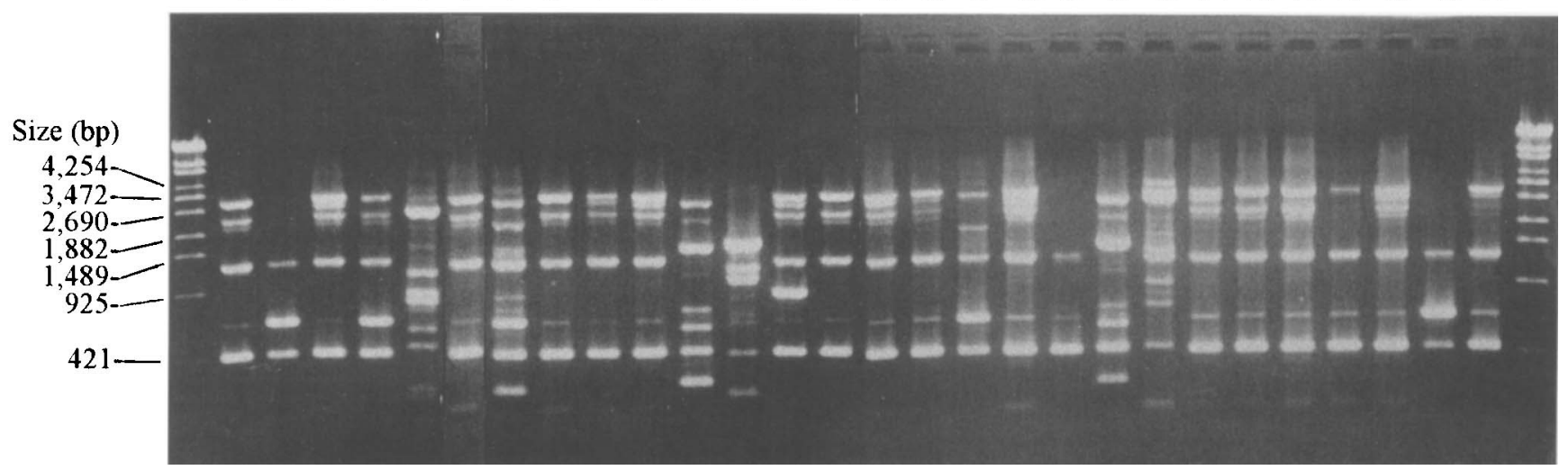

FIG. 1. RAPD-PCR band patterns of 28 strains of $T$. delbrueckii with decamer 2 as a primer. Each lane number corresponds to that of the strain in Table 1 .

IFO 1145 commonly assimilated D-glucosamine, maltose, methyl- $\alpha$-D-glucoside, glycerol, and ribitol as carbon sources and cadaverine as a nitrogen source and grew on $60 \%$ (weight/ weight) glucose agar. In addition, utilization of nitrite as the nitrogen source suggested that strain IFO 1145 could be a species of Debaryomyces, but the whole pattern of this strain did not coincide with any species accepted in Debaryomyces (3). Strains IFO 1138 and IFO 1956 revealed the same physiological profiles and could be discriminated from the other strains with respect to the following characteristics: no assimilation of trehalose, D-glucitol, D-mannitol, D-gluconate, or DLlactate; growth in the presence of $0.01 \%$ cycloheximide; no growth in the presence of $50 \%$ (weight/weight) glucose; and requirements of biotin, thiamine, niacin, and pantothenate.

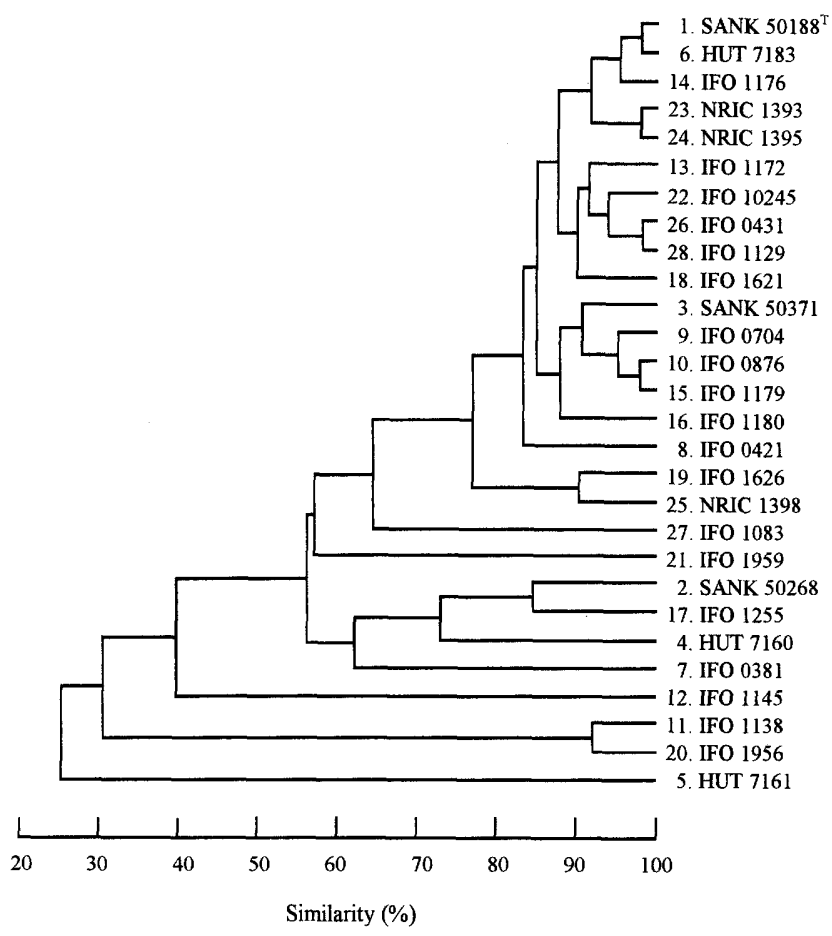

FIG. 2. Unrooted dendrogram based on RAPD-PCR patterns by the UPGMA method.
From identification keys involving physiological tests only (3), both strains were classified as either $S$. castellii or $S$. dairensis. Discrimination of these two taxa requires further analysis by molecular taxonomic methods (23).

Phylogenetic analysis with ITS sequences. The ITS regions of the eight strains were amplified, and their sequences were determined. Sizes of ITS1 and ITS2 were 293 and $259 \mathrm{bp}$ in strains SANK 50188 ${ }^{\mathrm{T}}$, IFO 0381, IFO 0421, and IFO 1959; 198 and 195 bp in strain HUT 7161; 279 and 246 bp in strains IFO 1138 and IFO 1956; and 262 and 198 bp in strain IFO 1145. Sequences of entire ITS regions $(710 \mathrm{bp})$ including the $5.8 \mathrm{~S}$ rRNA gene were identical among the four reference strains SANK 50188 ${ }^{\mathbf{T}}$, IFO 0381, IFO 0421, and IFO 1959, except for one base of ITS1 in strain IFO 0381. Strains IFO 1138 and IFO 1956 had the same sequence and exhibited $45.2 \%$ and $54.5 \%$ similarity to the type strain in their ITS1 and ITS2 regions, respectively. The remaining strains, HUT 7161 and IFO 1145, shared $34.3 \%$ similarity in ITS1 and $46.2 \%$ similarity in ITS2. Six base substitutions were found in the 5.8S rRNA genes (158 bp long) of these two strains as compared with those of the other strains examined. Because three of the six substituted bases differed in strain HUT 7161 and strain IFO 1145, these strains may represent distinct taxa.

The genetic relationships among the eight strains and other related species of the genera Torulaspora, Zygosaccharomyces, and Saccharomyces are shown in dendrograms (Fig. 3). Strains IFO 1138 and IFO 1956 were closely related to $S$. castellii but not to $S$. dairensis. Strain HUT 7161 was found among the Saccharomyces and Zygosaccharomyces species in the ITS1based tree probably because ITS1 regions have higher rates of divergence than ITS2 regions (10). On the basis of branching position, strains HUT 7161 and IFO 1145 were clearly not members of Torulaspora and had no close relationship to the other species.

\section{DISCUSSION}

RAPD-PCR analysis is a method for typing organisms and has also been shown to be suitable for the identification of certain yeasts $(1,5,11,14)$. One of the most important points in this method is the nucleotide sequence of the primer used (11). In the present experiments, we used three primers, decamer 1, decamer 2, and M13 (Table 2), which enabled Molnár et al. (15) to differentiate 10 species of Saccharomyces. Although Price et al. (18) reported that $S$. inconspicuus (= IFO 1621), $S$. vafer (= IFO 1626), and T. fermentati (= NRIC 1398) 

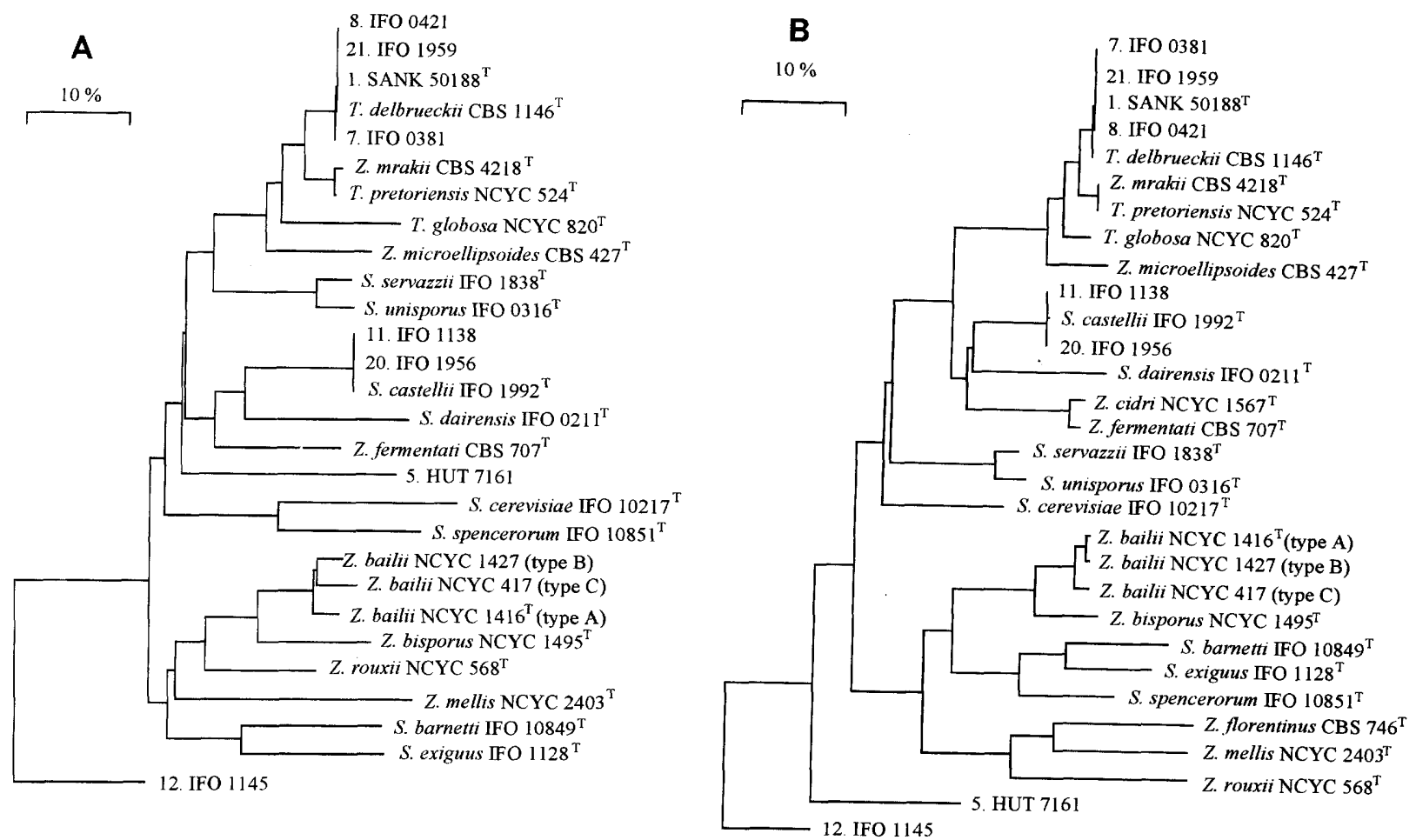

FIG. 3. Phylogenetic trees constructed by the neighbor-joining method from ITS1 sequences (A) and ITS2 sequences (B). Published sequences were used for the species of Torulaspora, Zygosaccharomyces, and Saccharomyces. Bar $=10 \%$ difference between sequences.

exhibited almost $100 \%$ DNA reassociation with the type strain of $T$. delbrueckii, the similarity values of these three strains compared with SANK $50188^{\mathrm{T}}$ on RAPD-PCR analysis were 88,77 , and $77 \%$, respectively. These discrepancies can indicate that RAPD-PCR analysis is more sensitive for differentiating the strains in the same species, but they indicate the possibility that the primers amplify certain specific sequences to elicit biased results. Therefore, we used RAPD-PCR analysis as the preliminary experiment to select the strains which were phylogenetically far from the type strain.

Conventional identification tests and sequence analysis of ITS regions showed that certain selected strains belonged to the taxa different from the genus Torulaspora. These findings are consistent with the previous observations that strains HUT 7161, IFO 1138, IFO 1145, and IFO 1956 were readily discriminated from the type strain by their electrophoretic karyotypes (16). About six chromosomal bands ranging from 800 to 1,600 $\mathrm{kb}$ were observed in most strains tested, including the type strain of $T$. delbrueckii. By contrast, chromosomes of strain HUT 7161 and strain IFO 1145 were larger than 1,000 kb and $2,000 \mathrm{~kb}$, respectively, and those of strains IFO 1138 and IFO 1956 varied from 500 to $2,300 \mathrm{~kb}$.

On the basis of the present results, strains HUT 7161 and IFO 1145 were grouped in the genus Debaryomyces, and the former strain may represent $D$. hansenii. The ascospore morphologies for many species in Saccharomyces group III, now incorporated into Torulaspora, were essentially identical and also frequently indistinguishable from those of the majority of species in Debaryomyces (21). These two strains might be incorrectly identified based on their morphological characteristics.

Strain IFO 1956 was originally identified as Torula alactosa, which has been moved to Candida holmii, the anamorph of $S$. exiguus (3). However, in the present experiments, this strain was shown to be closely related to ascosporogenous $S$. castellii together with strain IFO 1138. Since rarely formed ascospores could not be found, strain IFO 1956 may have been classified as an imperfect species. It is still unknown why strains IFO 1956 and IFO 1138 were misidentified in spite of the observations that physiological patterns of these strains fitted the descriptions of $S$. castellii and $S$. dairensis and not that of $T$. delbrueckii.

In conclusion, analyses of RAPD-PCR and ITS sequences are helpful in identifying yeast strains correctly in addition to morphological and physiological tests.

\section{ACKNOWLEDGMENT}

We thank Yoshimi Takenaka for her technical assistance.

\section{REFERENCES}

1. Baleiras Couto, M. M., B. J. Hartog, J. H. J. Huis in't Veld, H. Hofstra, and J. M. B. M. van der Vossen. 1996. Identification of spoilage yeasts in a food-production chain by microsatellite polymerase chain reaction fingerprinting. Food Microbiol 13:59-67.

2. Barnett, J. A. 1992. The taxonomy of the genus Saccharomyces Meyen ex Reess: a short review for non-taxonomists. Yeast 8:1-23.

3. Barnett, J. A., R. W. Payne, and D. Yarrow. 1990. Yeast: characteristics and identification, 2nd ed. Cambridge University Press, Cambridge, United Kingdom.

4. Benítez, T., L. Del Castillo, A. Aguilera, J. Conde, and E. Cerdá-Olmedo. 1983. Selection of wine yeast for growth and fermentation in the presence of ethanol and sucrose. Appl. Environ. Microbiol. 45:1429-1436.

5. Bostock, A., M. N. Khattak, R. Matthews, and J. Burnie. 1993. Comparison of PCR fingerprinting, by random amplification of polymorphic DNA, with other molecular typing methods for Candida albicans. J. Gen. Microbiol. 139:2179-2184.

6. Felsenstein, J. 1993. PHYLIP (Phylogenetic Inference Package) version 3.5c. Department of Genetics, University of Washington, Seattle, Wash.

7. Fukunaga, M., and A. Hamase. 1995. Outer surface protein C gene sequence analysis of Borrelia burgdorferi sensu lato isolates of Japan. J. Clin. Microbiol. 33:2415-2420.

8. Hansen, E. C. 1883 . Unders $ø$ gelser over alkoholgjaersvampenes fysiologi og 
morfologi. II. Om askosporedannelsen hos slaegten Saccharomyces. Medd. Carlsberg Lab. 2:29-86.

9. Higgines, D. G., A. K. Bleasby, and R. Fuchs. 1992. CLUSTAL V: improved software for multiple sequence alignment. Comput. Appl. Biosci. 8:189-191.

10. James, S. A., M. D. Collins, and I. N. Roberts. 1996. Use of an rRNA internal transcribed spacer region to distinguish phylogenetically closely related species of the genera Zygosaccharomyces and Torulaspora. Int. J. Syst. Bacteriol. 46: $189-194$.

11. Lieckfeldt, E., W. Meyer, and T. Börner. 1993. Rapid identification and differentiation of yeasts by DNA and PCR fingerprinting. J. Basic Microbiol. 33:413-426.

12. Lindner, P. 1895. Mikroskopische Betriebskontrolle in den Gärungsgewerben. P. Parey, Berlin, Germany.

13. Lodder, J., and N. J. W. Kreger-van Rij. 1952. The yeasts: a taxonomic study. North-Holland Publishing Co., Amsterdam, The Netherlands.

14. Messner, R., H. Prillinger, F. Altmann, K. Lopandic, K. Wimmer, O. Molnár, and F. Weigang. 1994. Molecular characterization and application of random amplified polymorphic DNA analysis of Mrakia and Sterigmatomyces species. Int. J. Syst. Bacteriol. 44:694-703.

15. Molnár, O., R. Messner, H. Prillinger, U. Stahl, and E. Slavikova. 1995 Genotypic identification of Saccharomyces species using random amplified polymorphic DNA analysis. Syst. Appl. Microbiol. 18:136-145.

16. Oda, Y., and K. Tonomura. 1995. Electrophoretic karyotyping of the yeast genus Torulaspora. Lett. Appl. Microbiol. 21:190-193.
17. Ohshima, Y., T. Sugaura, M. Horita, and T. Sasaki. 1987. Industrial application of artificially induced diploid strains of Torulaspora delbrueckii. Appl. Environ. Microbiol. 53:1512-1514.

18. Price, C. W., G. B. Fuson, and H. J. Phaff. 1978. Genome comparison in yeast systematics: delimitation of species within the genera Schwanniomyces, Saccharomyces, Debaryomyces, and Pichia. Microbiol. Rev. 42:161-193.

19. Saitou, N., and M. Nei. 1987. The neighbor-joining method: a new method for reconstructing phylogenetic trees. Mol. Biol. Evol. 4:161-193.

20. Valente, P., F. C. Gouveia, G. A. de Lemos, D. Pimentel, J. D. van Elsas, L. C. Mendonça-Hagler, and A. N. Hagler. 1996. PCR amplification of the rDNA internal transcribed spacer region for differentiation of Saccharomyces cultures. FEMS Microbiol. Lett. 137:253-256.

21. van der Walt, J. P. 1970. Saccharomyces emend. Reess, p. 555-718. In J. Lodder (ed.), The yeasts-a taxonomic study, 2nd ed. Elsevier Science Publishers, Amsterdam, The Netherlands.

22. van der Walt, J. P., and E. Johannsen. 1975. The genus Torulaspora Lindner. Counc. Sci. Ind. Res. Res. Rep. Pretoria 325:1-23.

23. Vaughan-Martini, A., and C. P. Kurtzman. 1988. Deoxyribonucleic acid relatedness among species of Saccharomyces sensu lato. Mycologia 80:241243.

24. Yarrow, D. 1984. Saccharomyces Meyen ex Reess, p. 379-395. In N. J. W. Kreger-van Rij (ed.), The yeasts--a taxonomic study, 3rd ed. Elsevier Science Publishers B. V., Amsterdam, The Netherlands. 